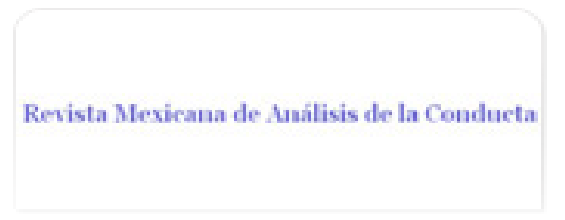

Revista Mexicana de Análisis de la Conducta ISSN: 0185-4534

editora@rmac-mx.org

Sociedad Mexicana de Análisis de la Conducta México

RANGEL-BERNAL, NORA EDITH; RIBES IÑESTA, EMILIO; VALDÉZ-GONZÁLEZ, VERÓNICA

TATIANA; PULIDO-ÁVALOS, LIZBETH

Las funciones de poder en la obediencia y el cumplimiento de niños escolares

Revista Mexicana de Análisis de la Conducta, vol. 37, núm. 2, 2011, pp. 205-227

Sociedad Mexicana de Análisis de la Conducta

Guadalajara, México

Disponible en: http://www.redalyc.org/articulo.oa?id=59319255012

- Cómo citar el artículo

- Número completo

- Más información del artículo

Página de la revista en redalyc.org

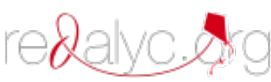

Sistema de Información Científica

Red de Revistas Científicas de América Latina, el Caribe, España y Portugal Proyecto académico sin fines de lucro, desarrollado bajo la iniciativa de acceso abierto 


\title{
LAS FUNCIONES DE PODER EN LA OBEDIENCIA Y EL CUMPLIMIENTO DE NIÑOS ESCOLARES
}

\author{
POWER FUNCTIONS IN SCHOOLCHILDREN'S \\ OBEDIENCE AND COMPLIANCE \\ NORA EDITH RANGEL-BERNAL ${ }^{1}$, EMILIO RIBES IÑESTA ${ }^{2}$, \\ VERÓNICA TATIANA VALDÉZ-GONZÁLEZ ${ }^{1}$ Y LIZBETH PULIDO-ÁVALOS ${ }^{1}$ \\ ${ }^{1}$ Centro de Estudios e Investigaciones en Comportamiento \\ Universidad de Guadalajara, Guadalajara, Jalisco, México \\ ${ }^{2}$ InSTITUTO DE PSICOLOGÍA Y EDUCACIÓN \\ Universidad Veracruzana, Xalapa, Veracruz, México
}

\begin{abstract}
Resumen
Se realizaron dos experimentos para evaluar el efecto de las funciones de poder propuestas por Ribes (2001) en el cumplimiento y en la obediencia de niños escolares. En el Experimento 1 se comparó el efecto de estas funciones establecidas por: a) la intervención del experimentador quien, en una primera fase, se desempeñó como una figura de autoridad que basó su poder en la fuerza (obediencia), y b) la familiarización con el experimentador sin función de autoridad en la situación experimental (cumplimiento). Mientras que en el Experimento 2, en la primera fase, el experimentador se desempeñó como una figura de autoridad que basó su poder en la riqueza (obediencia). Se encontró que los participantes que se expusieron a una figura de autoridad por fuerza fueron más obedientes que los que se expusieron a condiciones de poder por riqueza y de familiarización con el experimentador.

Palabras clave: Poder, autoridad, obediencia, cumplimiento, fuerza, riqueza.
\end{abstract}

Estos estudios fueron realizados en el marco de la tesis doctoral del primer autor, quien agradece al Consejo Nacional de Ciencia y Tecnología por la beca otorgada para la realización de los mismos. Este artículo es parte de la tesis doctoral de la primera autora, realizada bajo la supervisión del segundo autor. Verónica Valdez y Lizbeth Pulido Ávalos participaron en la realización de los experimentos y en el análisis de datos, así como en la revisión y comentarios del documento final. Dirigir la correspondencia a la primera autora, al Centro de Estudios e Investigaciones en Comportamiento, Francisco de Quevedo 180, Col. Arcos Vallarta, Guadalajara, Jalisco. C.P. 44130 , email: norarangel@cucba.udg.mx 


\begin{abstract}
Two experiments were designed to evaluate the effects of power functions proposed by Ribes (2001) in schoolchildren's obedience and compliance. In the Experiment 1,the effect of these functions were compared by the establishment of: 1) the experimenter intervention, who in a first phase of the experiments, he acted like an authority figure with power based on the force (obedience), and b) the familiarization with the experimenter without authority function in the experimental situation (compliance). Meanwhile in the Experiment 2, the experimenter acted like an authority figure with power based on the richness (obedience). It was found that participants exposed to an authority with power based on the force were more obedient that participants exposed to an authority with power based on the richness, and participants exposed to conditions of familiarization with the experimenter.
\end{abstract}

Key words: Power, authority, obedience, compliance, force, richness

La obediencia y el cumplimiento son fenómenos que han interesado a los psicólogos desde hace tiempo. Así, desde la llamada Psicología Social, la obediencia ha sido definida como el cambio de conducta por parte de un individuo en respuesta a un mandato directo de otro (Baron \& Byrne, 1982) bajo el reconocimiento de su legitimidad para mandar; mientras que el cumplimiento se ha definido como el cambio de conducta por parte de un individuo en respuesta a peticiones directas de otros (Baron \& Byrne, 1982), peticiones que pueden hacerse de manera explícita o implícita (Cialdini \& Goldstein, 2004).

De las definiciones planteadas, puede observarse que el énfasis de la distinción entre los dos fenómenos se ha puesto en la forma en la que se produce el cambio en la conducta de otros, es decir, a través de órdenes dadas (e.g. Blass, 1996; Brant, 1990; Burger, 2009; Milgram, 1974/2004) o de peticiones realizadas (e.g. Baron \& Byrne, 1982; Burger, 1986; Cialdini \& Goldstein, 2004; Rind, 1997; Rindt \& Strohmetz, 2001).

Sin embargo, si se analiza el caso del Análisis de la Conducta, esta distinción, en algunos casos, parece no seguirse. Desde esta perspectiva, existen estudios en los que se pretende analizar el cumplimiento en niños a quienes se presenta una instrucción muy precisa esperando que el niño realice lo que se le ha 'pedido' en intervalos temporales cortos. Si lo hace, generalmente se le elogia, y si no lo hace, se le castiga (e.g. Roberts, Hatzenbuehler \& Bean, 1981; Robinson \& Sheridan, 2000; Wilder, Harris, Reagan \& Rasey, 2007). En el caso de estos estudios puede observarse que, en realidad, a los niños no se les presenta una petición ante la cual responder o no voluntariamente, sino que, por el contrario, los niños tienen la obligación de obedecer ante la amenaza de un castigo. Por ello, en el presente trabajo se plantea que, bajo la distinción realizada por la Psicología Social, estos estudios se relacionan con la obediencia y no con el cumplimiento. De hecho, autores como Ayala et al. 
(2001) y Ayala, Téllez \& Gutiérrez (1994), han utilizado este tipo de procedimientos para estudiar explícitamente el fenómeno de la obediencia.

Aunque la distinción entre la obediencia y el cumplimiento es clara a partir de las definiciones planteadas por la Psicología Social, pareciera que estos efectos surgen exclusivamente de la forma en la que se les demanda (a través de órdenes y/o peticiones) independientemente de las condiciones en las que dichas formas se presentan en una situación particular. Así, en el presente trabajo se propone que la obediencia y el cumplimiento además de ser fenómenos distintos entre sí, surgen como efectos del establecimiento de relaciones funcionales distintas entre el poder y la autoridad (para una exposición detallada ver Rangel, 2008; Rangel \& Ribes, 2009a, Ribes, Rangel \& López, 2008).

Con respecto a las relaciones posibles entre el poder y la autoridad, Russell (1949) reconoció que la influencia que un individuo pudiera tener sobre otros, dependería del tipo de poder en que ésta se apoyara. Afirmó que dicho poder podía ser de tres tipos: basado en la fuerza, basado en la riqueza, y/o basado en el conocimiento, señalando que el poder por riqueza era el más débil de los tres, debido a que los individuos no reconocían ningún derecho legítimo en quien lo ejercía. Así, se plantea que cualquiera que sea la base del poder de un individuo en una situación particular, de acuerdo con López (1987) y Ribes (2001), éste puede establecerse mediante una o más de las siguientes funciones: prescripción, regulación, supervisión y administración de consecuencias ante la conducta de los individuos. Siguiendo a Ribes (2001) la función de prescripción se establece mediante la estipulación de las actividades que se pueden o deben realizar en una situación, así como las consecuencias correspondientes; la función de regulación se establece cuando la figura de autoridad interviene para hacer ajustes en la situación, haciendo que se mantengan las condiciones prescritas; la función de supervisión tiene lugar vigilando que se cumpla con lo prescrito y señalando su no cumplimiento; mientras que la función de administración tiene lugar mediante la procuración de consecuencias.

Llevando al ámbito experimental esta propuesta, Rangel \& Ribes (2009b) compararon los efectos en la obediencia de niños de primaria que resolvieron una tarea ante una figura de autoridad que sólo prescribió y reguló las interacciones, con la obediencia presentada ante una figura de autoridad que cumplió con las cuatro funciones de poder. Los resultados mostraron que los niños que se expusieron a la figura de autoridad que ejerció las cuatro funciones de poder fueron más obedientes que los que se expusieron a la autoridad que sólo ejerció dos funciones. Sin embargo, no quedó claro el papel que, por separado, pudieran tener cada una de las funciones en la obediencia de los niños.

Por lo anterior, se planearon dos experimentos para evaluar el efecto de cada una de las funciones de poder en la obediencia de niños de primaria. Bajo el supuesto de que el establecimiento de las funciones de poder y de su efecto en los influidos es diferencial dependiendo del poder en el cual se sustenten, se evaluó el efecto de dichas funciones en la obediencia de los niños después de haber sido expuestos 
a una figura de autoridad cuyo poder se basó en la fuerza (Experimento 1) o en la riqueza (Experimento 2). Además, en el Experimento 1 se evaluó el efecto de cada una de las funciones de poder en el cumplimiento de niños de primaria después de haber sido expuestos a un período de familiarización con el experimentador (con familiarización se hace referencia a que no se implementaron manipulaciones explícitas para establecer algún tipo de autoridad del experimentador frente a los participantes).

\section{Método del Experimento 1}

\section{Participantes}

36 niños que cursaban el quinto o el sexto grado de primaria (18 mujeres y 18 hombres) entre los 9 y los 11 años de edad, participaron en el experimento a cambio de dulces y golosinas. Con base en el procedimiento de muestreo de reforzadores propuesto por Ayllon y Azrin (1968) los premios, con su respectivo valor en puntos, se mostraron a los participantes antes de iniciar la sesión experimental.

Materiales y situación experimental

Para la realización del experimento se utilizaron dos tipos de tareas: 1) rompecabezas de 100 piezas, y 2) sopas de letras, que se presentaron impresas, conformadas por dos listas de 8 palabras cada una. Se utilizó también un cronómetro, y los datos se graficaron mediante el programa Sigma Plot 8.0. Las sesiones se realizaron de lunes a viernes en un salón de una escuela primaria. Cada participante colaboró en el experimento durante 4 días.

\section{Diseño}

En la Tabla 1 se describe el diseño que se utilizó en este experimento. Consistió en una comparación intrasujeto y entre sujetos bajo distintos tratamientos experimentales. Los participantes se distribuyeron al azar en nueve grupos. En la primera fase del experimento, los participantes de los grupos 1, 2, 3, 4 y 4B se expusieron a una condición de Familiarización con el experimentador, mientras que los grupos 5, 6, 7 y 8 se expusieron a un período de elección de tarea seguido por uno de Entrenamiento en Autoridad. Durante la Fase 2, todos los participantes se expusieron, colectivamente, a una condición de Línea Base. Posteriormente, durante las fases 3 (individual) y 4 (colectiva), todos los grupos se expusieron diferencialmente a una de las 4 funciones de poder descritas anteriormente (prescripción, regulación, supervisión y administración de consecuencias) (ver Tabla 1). 
Tabla 1.

Muestra el Diseño Experimental empleado en este experimento.

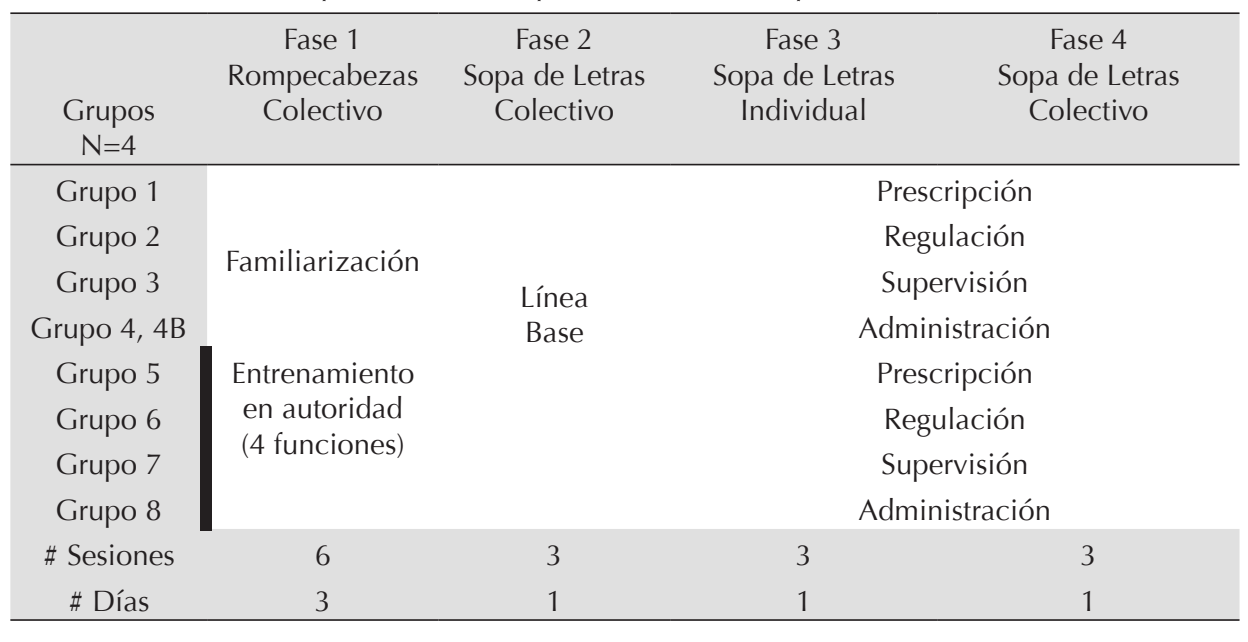

Deríodo de elección de la tarea experimental.

\section{Procedimiento}

Período de elección de la tarea experimental

Antes del periodo de Entrenamiento en Autoridad, los participantes de los grupos 5, 6,7 y 8 eligieron entre tres tareas disponibles en la situación: leer un texto, copiar un texto o armar un rompecabezas. Sólo se incluyeron en el experimento los participantes que, en una sesión de 15 minutos, pasaron por lo menos 10 minutos armando rompecabezas. Lo anterior se realizó con base en el procedimiento propuesto por Premack (1962; 1963), para asegurar que la expulsión de los niños de la situación experimental, en donde estarían armando rompecabezas, tendría un efecto aversivo para ellos y permitiría al experimentador colocarse como una figura de autoridad por fuerza. Las instrucciones que se presentaron a los participantes fueron las siguientes:

A partir de este momento y durante los siguientes 15 minutos ustedes pueden hacer lo que más les guste. Pueden leer, copiar un texto o armar rompecabezas. ¡Adelante!

Fase 1

Condición de Familiarización Los participantes resolvieron rompecabezas de 100 piezas. Se siguió el procedimiento utilizado por Camacho (2000) en situaciones de competencia, en el que dos niños armaron dos rompecabezas en una misma mesa. Cada uno de los niños tenía un 
conjunto de piezas, en el que la mitad de ellas correspondía a su rompecabezas y la otra mitad correspondía al rompecabezas que iba a resolver su compañero. Esta condición obligaba a que se produjera un intercambio entre ellos para poder ensamblar los dos rompecabezas. Debido a que se ofreció un premio para el participante que terminara primero, o que colocara correctamente el mayor número de piezas del rompecabezas en un tiempo predeterminado por el experimentador, Camacho (2000) observó conductas competitivas y coercitivas por parte de los participantes en el transcurso de la sesión. En el presente experimento se utilizó este procedimiento con algunas modificaciones. Los dos rompecabezas fueron ensamblados por dos díadas de niños con el fin de incrementar la posibilidad de emisión de conductas coercitivas (que en este experimento se establecieron como no permitidas) por la cantidad de niños interactuando en la situación, y sobre todo, con el fin de dar el mismo tratamiento a los cuatro niños que formaron parte de cada grupo.

Se realizaron dos sesiones diarias, de treinta minutos cada una, durante tres días. Al inicio de esta condición, el experimentador fue presentado por el maestro de los niños diciendo: 'Él es (nombre del experimentador) y ustedes participarán en algunas actividades con él.' Las siguientes instrucciones se presentaron verbalmente:

En el siguiente juego, ustedes tienen que armar el rompecabezas de la figura que está a su lado derecho. Para completarlo necesitarán algunas de las piezas que tienen sus compañeros del otro equipo. Para conseguirlas ustedes se arreglan como quieran. Solamente tienen treinta minutos para resolverlo. El primer equipo que finalice su rompecabezas, o que al acabarse el tiempo haya ensamblado más piezas será el ganador. Mientras estén resolviendo los rompecabezas les pido que no digan malas palabras, se golpeen, se lastimen, se insulten, griten o levanten la voz a un compañero. iiiSuerte a los dos equipos!!!

Cabe aclarar que esta condición se realizó a manera de control, ya que si el objetivo del estudio era probar el papel de las funciones de poder en la obediencia de niños escolares, se debía contar con una condición en la que no se promoviera el establecimiento de dichas funciones. Por lo anterior, los 4 grupos expuestos a la condición de familiarización en este experimento, también sirvieron de comparación en el Experimento 2.

\section{Condición de Entrenamiento en autoridad}

En los grupos 5, 6, 7 y 8, el experimentador fue presentado por los maestros y el director diciendo 'Él (refiriéndose al experimentador) tiene toda mi autoridad en esta situación'. La dinámica fue similar a la de la condición de familiarización, sólo que durante esta condición el experimentador cumplió con las cuatro funciones de poder propuestas por Ribes (2001): prescribió, reguló, supervisó y administró consecuencias en la situación. La forma de ejercer las funciones fue la siguiente: a) Prescripción: el experimentador mencionó las instrucciones a los participantes y les prohibió algunas conductas estableciendo las consecuencias, si tales conductas se presentaban; b) 
Regulación: una vez que los participantes iniciaron con la tarea experimental, cada 5 minutos, el experimentador les indicó cuánto tiempo les quedaba para resolver la tarea y mantuvo a los participantes en la condición experimental; c) Supervisión: el experimentador vigiló y les indicó a los participantes cuando se estaban comportando de manera no permitida en la situación; y d) Administración de consecuencias: el experimentador retiró a los niños del juego cuando se comportaron de manera prohibida (poder por fuerza). Las instrucciones fueron similares a las de la condición de familiarización, con la diferencia siguiente:

...Mientras estén resolviendo los rompecabezas les prohíbo que digan malas palabras, se golpeen, se lastimen, se insulten, griten o levanten la voz a un compañero. Si lo hacen tendré que sacarlos del juego.

\section{Fase 2 - Línea Base}

Los participantes resolvieron juegos de Sopa de letras, una distinta para cada sesión, durante tres sesiones. Cada sopa de letras estuvo formada por 8 palabras en una lista roja y 8 palabras en una lista azul. Los participantes pudieron encontrar las palabras de cualquiera de las dos listas. Tuvieron 10 minutos para resolver cada sopa de letras. La Figura 1 muestra un ejemplo de la tarea como se le presentó a los participantes. Las instrucciones que se presentaron fueron las siguientes:

A continuación van a jugar encerrando las palabras que encuentren en la sopa de letras. Como pueden ver, tienen dos listas con palabras: una roja y una azul. Solamente tienen diez minutos para encontrar las palabras. ¡Suerte y adelante!

Fases 3 y 4

Durante estas fases, el experimentador ejerció en cada grupo, una de las cuatro funciones de poder. Los aspectos de la tarea que permanecieron constantes fueron los siguientes: los participantes resolvieron juegos de sopa de letras formados por 8 palabras en una lista roja y 8 palabras en una lista azul. Cada palabra encontrada de la lista azul tenía un valor de 10 puntos; mientras que cada palabra encontrada de la lista roja tenía un valor de 40 puntos. Dependiendo de la condición se les pedía o se les ordenaba que no encerraran palabras de la lista roja. Tuvieron diez minutos para resolver cada sopa de letras. Si los participantes terminaban de encontrar las palabras de la lista azul antes de que transcurriera este tiempo, tenían que permanecer en el cubículo experimental, con el fin de observar si, aún con el tiempo de espera, los niños cumplían con lo solicitado no encerrando palabras de la lista roja. Al finalizar cada sesión, el experimentador contó frente a cada participante los puntos que obtuvo y se realizó el intercambio por dulces y golosinas. Cabe aclarar que los participantes podían obtener los premios más grandes sólo si encontraban palabras de la lista roja (no permitida). 


\section{ANIMALES}

\begin{tabular}{|cccccccccccc|}
\hline A & S & E & R & P & I & E & N & T & E & N & O \\
I & N & U & O & A & L & M & L & A & L & U & L \\
L & C & O & N & E & J & O & I & C & E & C & L \\
O & A & J & I & A & R & S & A & U & F & O & I \\
C & I & G & U & U & C & Q & U & C & A & C & R \\
A & C & A & G & N & G & U & S & A & N & O & R \\
R & O & N & N & O & A & I & N & R & T & D & O \\
A & A & I & I & R & V & T & A & A & E & R & Z \\
C & G & L & P & U & I & O & H & C & S & I & N \\
O & R & L & C & B & S & Z & N & H & C & L & O \\
I & M & A & R & I & P & O & S & A & I & O & O \\
I & O & G & A & T & A & G & U & I & L & A & O \\
\hline
\end{tabular}
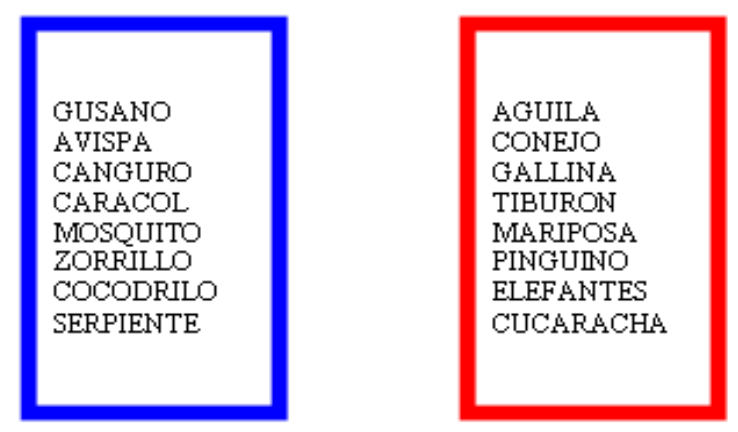

Figura 1. Ejemplo de la tarea de sopa de letras empleada. 
A continuación se describen las particularidades que pretendían el establecimiento de cada una de las funciones de poder en cada grupo del experimento.

Condición de prescripción.

Antes de que los participantes iniciaran la tarea de sopa de letras, el experimentador les ordenó que no encerraran las palabras de la lista roja advirtiéndoles que por cada palabra de esa lista que encerraran perderían 20 puntos. Sin embargo, al final de la sesión no se realizó el descuento de los puntos. Las instrucciones se presentaron oralmente y fueron las siguientes:

A continuación vas a jugar encerrando las palabras que encuentres en la sopa de letras. Cómo puedes ver tienes dos listas con palabras: una roja y una azul. Por cada palabra de la lista roja que encuentres en la sopa obtendrás 40 puntos, mientras que por cada palabra de la lista azul que encuentres en la sopa obtendrás 10 puntos. Únicamente debes buscar las palabras de la lista azul, pues las de la lista roja está prohibido encerrarlas. Solamente tienes diez minutos para encontrar las palabras. Si terminas antes de los diez minutos, tendrás que permanecer sentado hasta que te lo indique. En ese momento podrás intercambiar tus puntos por premios. ¡Te prohíbo encerrar las palabras de la lista roja. Si lo haces perderás 20 puntos por cada palabra!

Condición de Regulación.

Antes de que los participantes iniciaran la tarea de sopa de letras, el experimentador les pidió que no encerraran palabras de la lista roja, sólo las de la lista azul. No hubo sanciones si los participantes encerraban palabras de la lista roja. Cada 5 minutos, el experimentador les decía a los participantes cuánto tiempo les quedaba para terminar la sesión y mantuvo a los participantes realizando la tarea. Las instrucciones fueron similares a las de la condición de prescripción, sólo se modificó lo siguiente:

...En esta ocasión me gustaría pedirte que sólo busques las palabras de la lista azul. Solamente tienes diez minutos para encontrar las palabras. Yo te voy a ir diciendo cuánto tiempo te queda. Si terminas...indique. Recuerda que te pedí que no encierres las palabras de la lista roja.

Condición de Supervisión.

A diferencia de la condición de Regulación cada vez que los participantes encerraban una palabra en la lista roja el experimentador les decía 'recuerda que te pedí que no encierres palabras de la lista roja'. Las instrucciones fueron similares a las de la condición de regulación, sólo se eliminó la parte referente al tiempo de sesión restante.

Condición de Administración en el Grupo 4.

Si los participantes encerraban una palabra de la lista roja, sin aviso, el experimentador les retiraba la hoja de la sopa de letras y les decía que había terminado la sesión. 
Con la finalidad de mantener constante la situación con el resto de las condiciones experimentales, los participantes intercambiaron los puntos que habían ganado hasta ese momento de la sesión. Las instrucciones fueron similares a las de la condición de regulación, sólo se eliminó la parte referente al tiempo de sesión restante.

Condición de Administración en el Grupo $4 B$ y 8.

Debido a que en la condición anterior no se tenía claro si la petición de solo responder en la lista azul funcionaría como una prescripción para los participantes, se decidió realizar este control en donde se eliminó la petición de no responder en la lista azul y únicamente administrar la consecuencia de retirar la hoja de la sopa de letras si encerraban una palabra de la lista roja. Los participantes intercambiaron los puntos que habían ganado hasta ese momento de la sesión.

\section{Resultados y discusión}

La Figura 2 muestra el número de palabras encontradas en cada lista por los participantes de los grupos 1, 2 y 3 . Todos los participantes respondieron en las dos listas durante las tres sesiones de Línea Base (LB1, LB2, LB3). Los participantes del Grupo 2 mostraron una menor cantidad de conductas de incumplimiento (respuestas en la lista roja). La mayoría de los participantes de los grupos 1 y 3 respondieron sólo en la lista azul durante las sesiones individuales $(11,12,13)$ y respondieron tanto en la lista azul como en la lista roja durante algunas de las sesiones colectivas (C1, C2, C3).

La Figura 3 muestra los resultados de los grupos 4 y 4B cuyos participantes también respondieron en las dos listas durante las tres sesiones de Línea Base. Mientras que con excepción del Participante 15, todos los participantes del Grupo 4 se mantuvieron respondiendo en la lista azul, todos los participantes del Grupo 4B se mantuvieron respondiendo en la lista roja durante todo el experimento. Los resultados observados en el Grupo 4 (baja frecuencia de respuestas en la lista roja), podrían sugerir que la petición a los participantes de no responder en la lista roja, pudo haber funcionado como un tipo de prescripción y, en concordancia con los resultados reportados por Rangel \& Ribes (2009b), el ejercicio de una combinación de funciones por una figura de autoridad podría generar una mayor cantidad de respuestas obedientes en los participantes.

La Figura 4 muestra los resultados de los participantes de los grupos 5, 6, 7 y 8, estos cuatro grupos se expusieron al entrenamiento de autoridad por fuerza. Al igual que los participantes de los grupos anteriores, estos respondieron en ambas listas durante las tres sesiones de Línea Base. Los participantes del Grupo 5 (Prescripción) fueron los que dejaron de responder en la lista prohibida en mayor medida, seguidos de los participantes de los grupos 6 (Regulación) y 7 (Supervisión). Finalmente, los participantes del Grupo 8 (Administración sin petición) se mantuvieron respondiendo en la lista roja durante todo el experimento. El Participante 26 desertó del experimento al concluir la tercera fase. 
Obediencia y cumplimiento en niños escolares
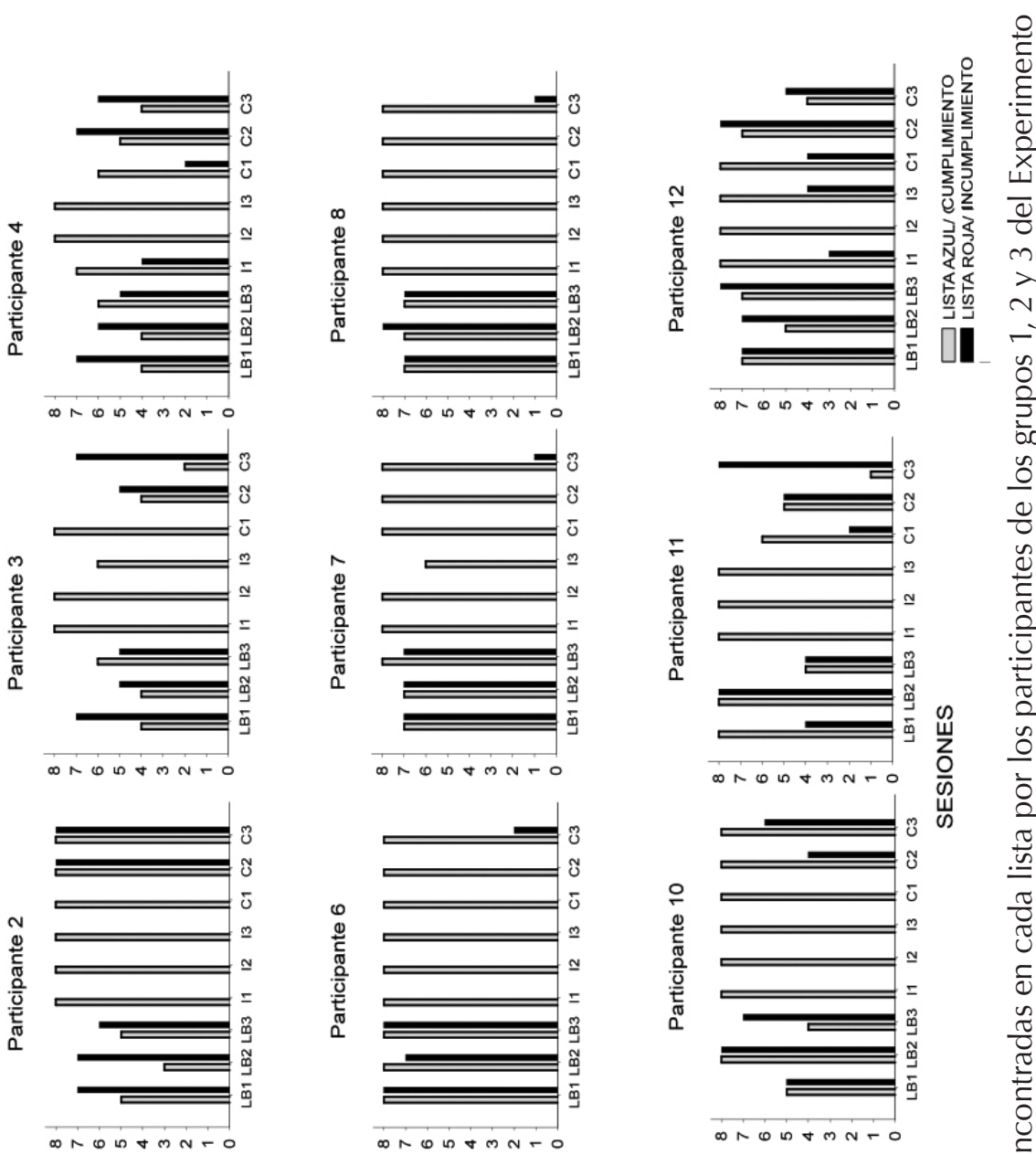

$\oplus$
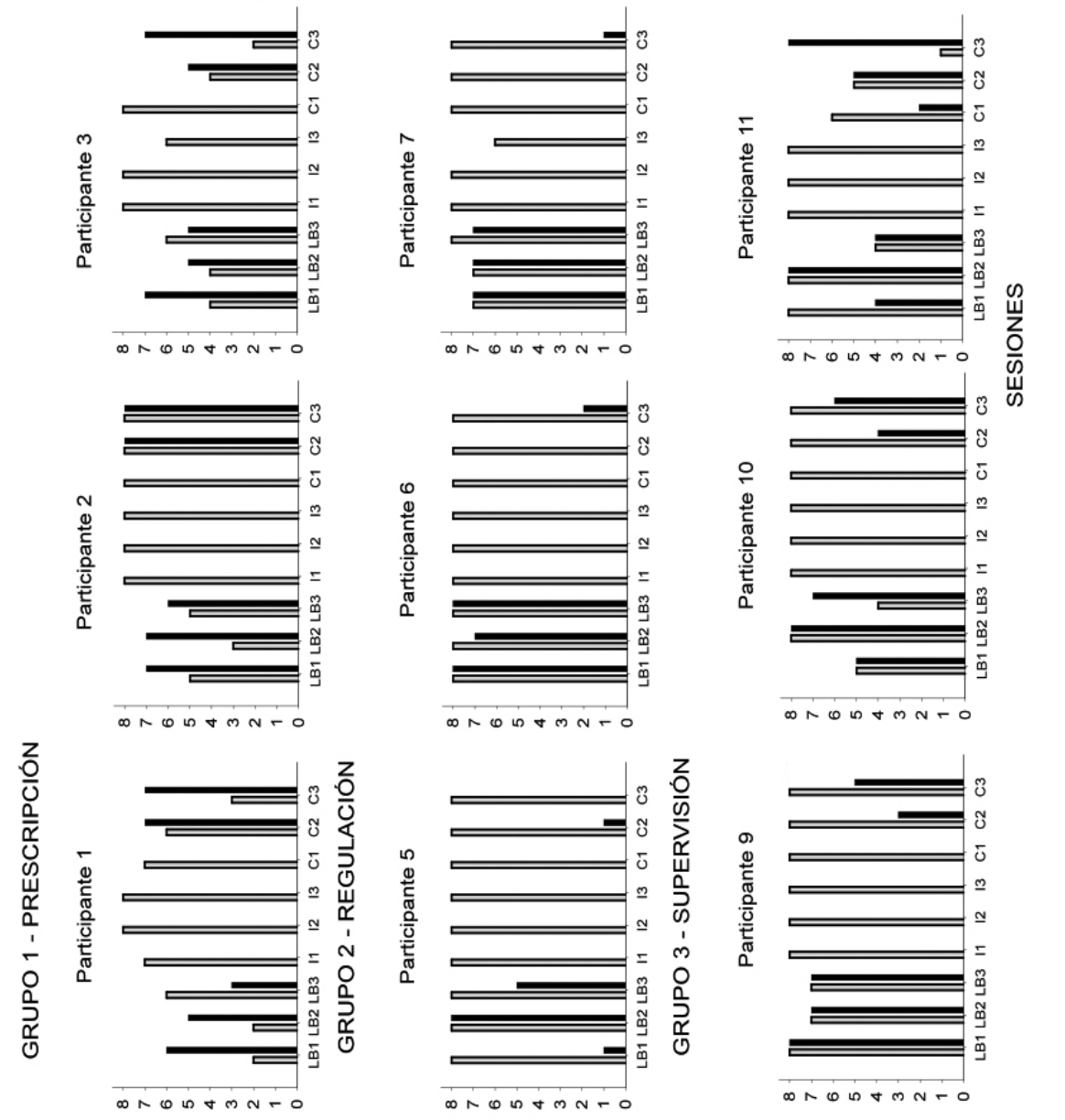

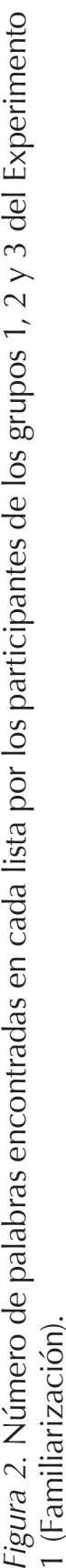



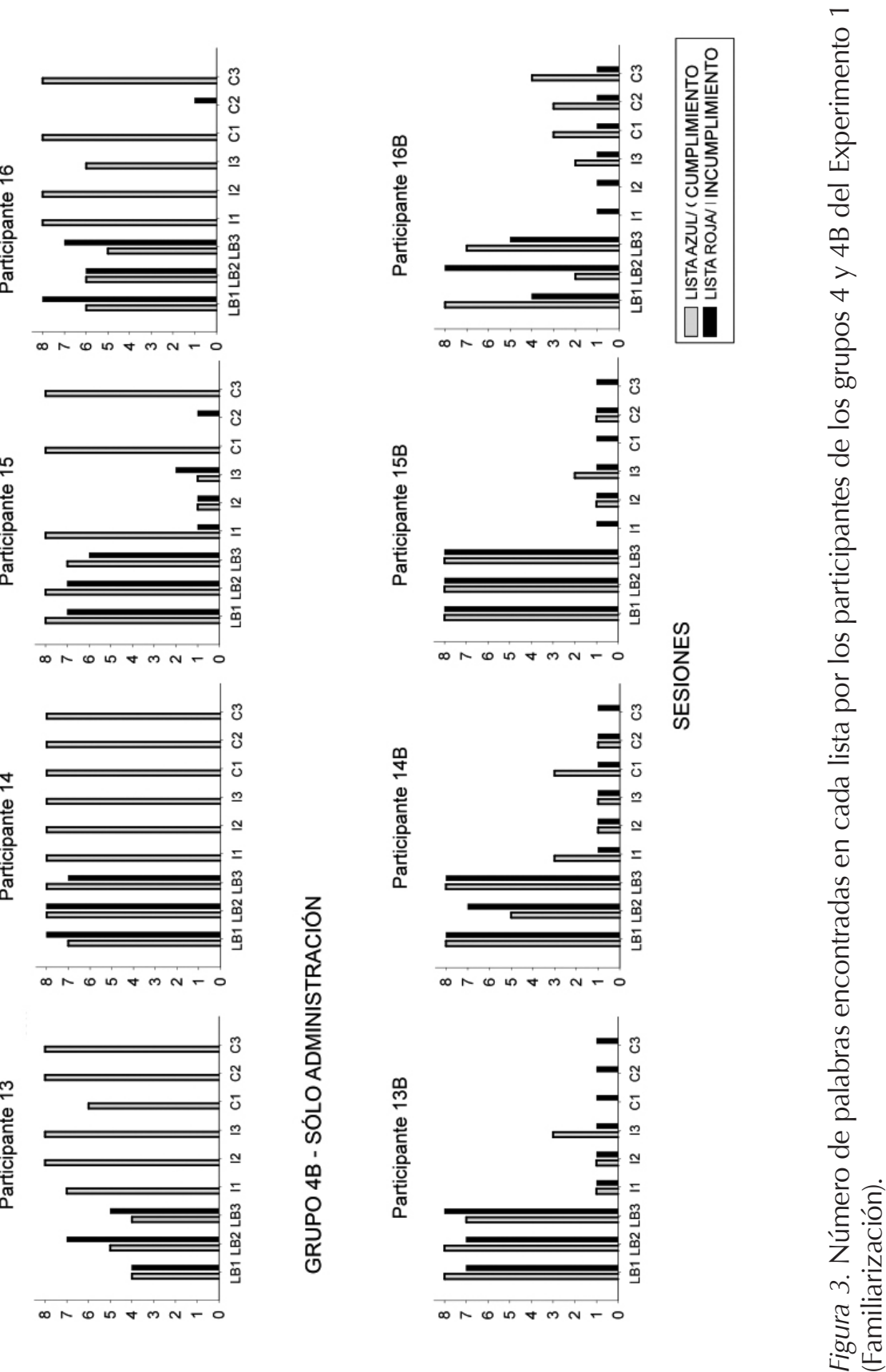

Revista Mexicana de Análisis de la Conducta / Mexican Journal of Behavior Analysis v37 n2 8-2011/11-2011 
Obediencia y cumplimiento en niños escolares
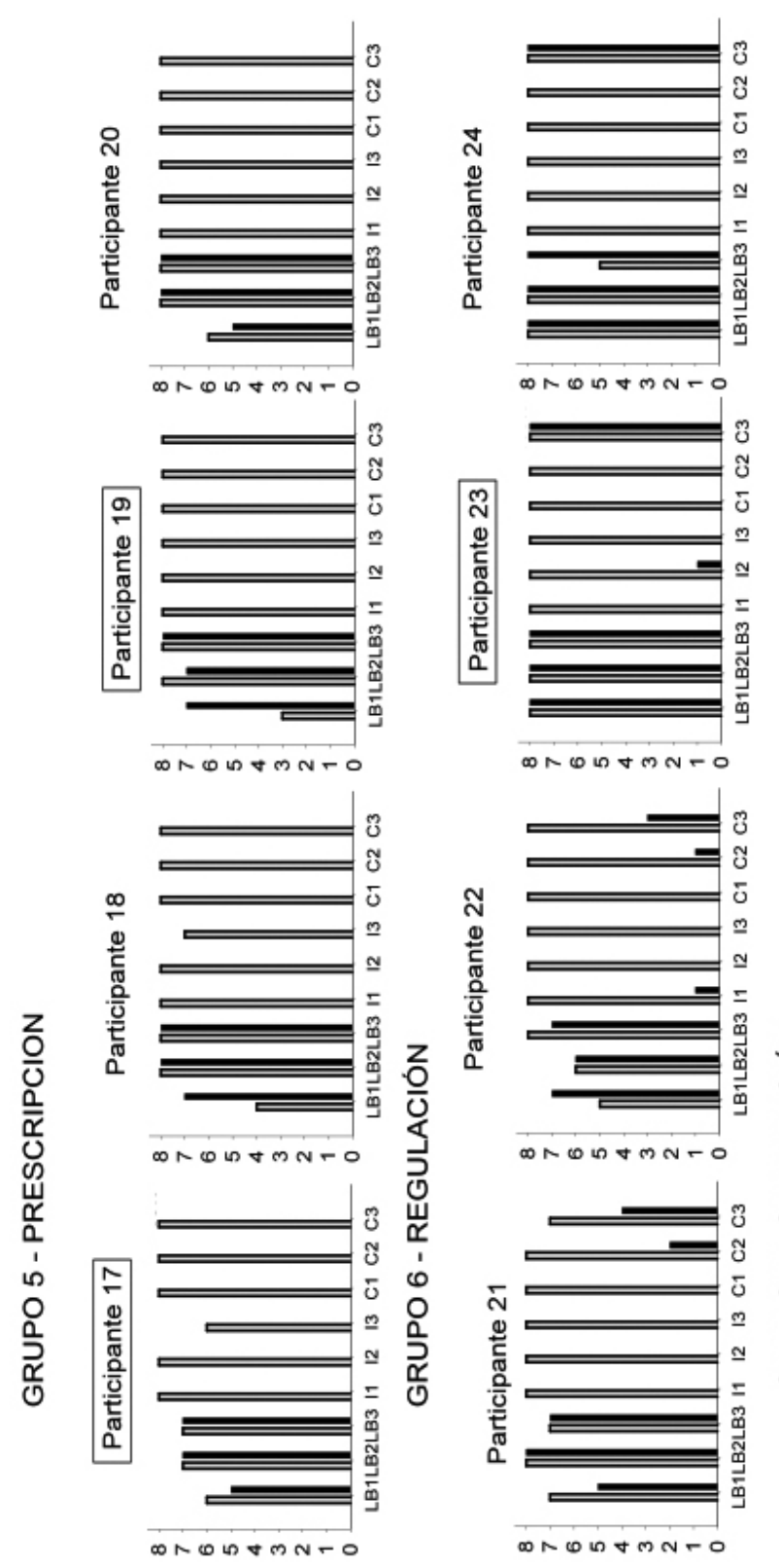

$\stackrel{0}{=}$

ฮิ

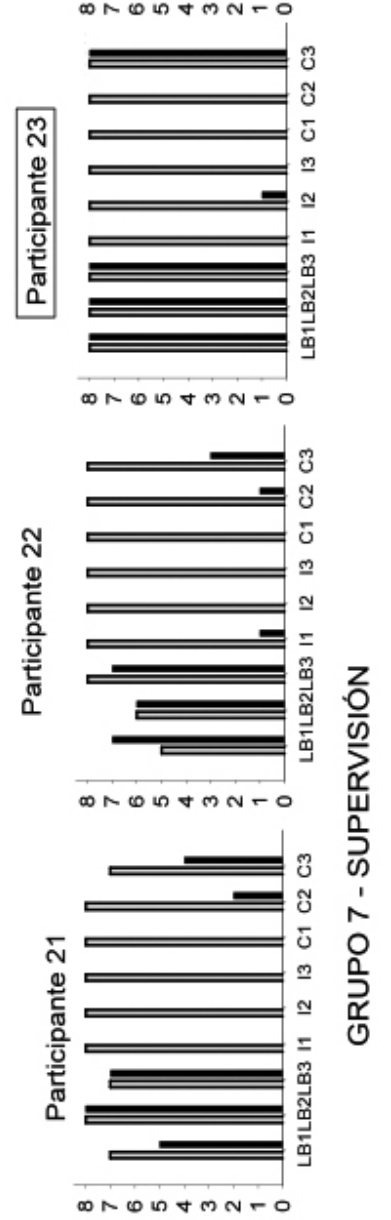

$\oplus$

Revista Mexicana de Análisis de la Conducta / Mexican Journal of Behavior Analysis v37 n2 8-2011/11-2011 


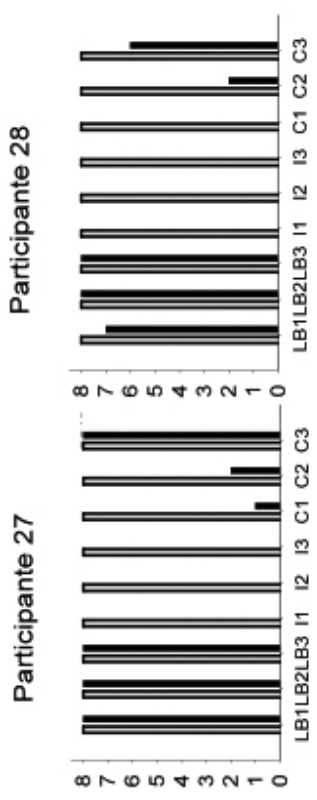

$\oplus$

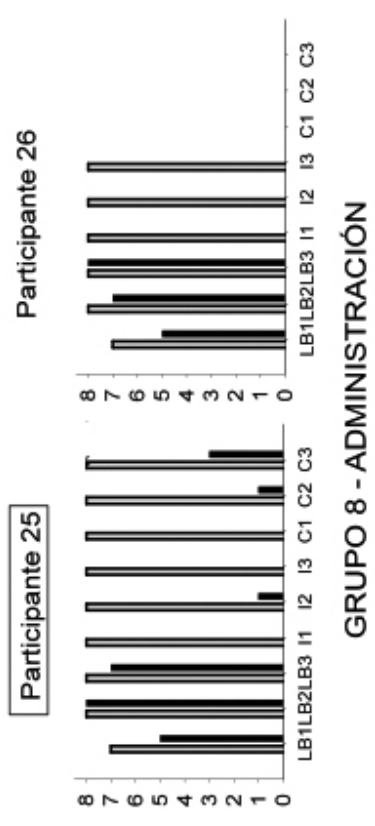

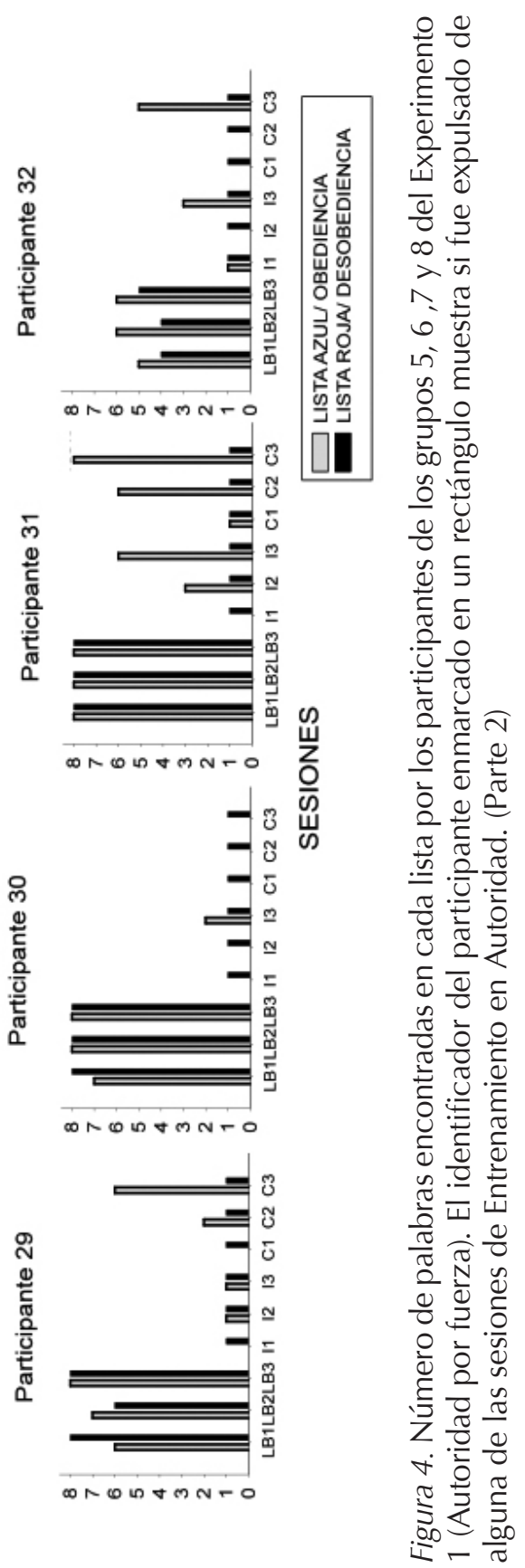


Los resultados encontrados en los participantes de los grupos 4B y 8 sugieren que el sólo ejercicio de la función de Administración no fue efectivo en la evitación de conductas de incumplimiento, ni de conductas desobedientes. Durante esta condición no se observaron efectos diferenciales en los participantes expuestos al período de familiarización o en los que se expusieron al entrenamiento ante una figura de autoridad. Este efecto pudo deberse a que en el Grupo 8 ninguno de los participantes fue retirado de la situación experimental al no realizar respuestas prohibidas. Este hecho pudo evitar que los participantes se expusieran a un verdadero entrenamiento ante una figura de autoridad ya que, como lo mencionaron Baron y Byrne (1982), dos aspectos que son fundamentales para que se presente el fenómeno de la obediencia son, por una parte, el establecimiento de una figura de autoridad en la situación, y por la otra, la habilidad que esta figura posee para administrar castigos a quienes desobedezcan. En el caso del Grupo 8, la figura de autoridad no tuvo la oportunidad de administrar castigos a los participantes puesto que no mostraron conductas prohibidas en las sesiones de Entrenamiento en autoridad (ver Figura 4).

Por otro lado, este resultado puede estar relacionado con un procedimiento de restitución por parte de los participantes, como fue encontrado por Rangel (2003). En este procedimiento de sobrecorrección se requiere que el sujeto que toma algo que no es suyo, lo devuelva (Azrin \& Wexolowski, 1974; Carey \& Bucher, 1981). Según estos autores, este procedimiento genera una disminución en la frecuencia de conductas indeseables. Sin embargo, Rangel (2003) reportó un efecto contrario: cuando se impuso a los participantes un costo de respuesta por realizar la conducta prohibida, estos justificaron su desobediencia mencionando que de cualquier manera se les iba a quitar cierta cantidad de puntos por desobedecer, y con ello, estarían restituyendo lo que obtuvieron de forma no permitida. Al parecer, en el presente experimento se encontraron resultados similares, ya que en los grupos en los que el experimentador ejerció funciones que permitieron 'castigar' inmediatamente la realización de conductas prohibidas, como es el caso de la supervisión y de la administración de consecuencias, se observaron más conductas desobedientes o de incumplimiento. Aún así, los resultados del Grupo 2 (Familiarización), en el que se ejerció la función de Regulación, y en el que los participantes mostraron muy pocas respuestas de incumplimiento, requiere de investigación adicional.

En resumen, a diferencia de los experimentos reportados por Rangel \& Ribes (2009b), en los que se evaluó el establecimiento de dos o cuatro funciones de poder, el presente experimento permitió evaluar los efectos diferenciales del establecimiento de cada una de las funciones de poder en la conducta de desobediencia o de incumplimiento por parte de los participantes, después de que la figura de autoridad fuera o no fuera establecida en la situación. Se pudo observar que en la situación de Familiarización, cuando el experimentador ejerció la función de Regulación, los participantes no mostraron conductas de incumplimiento, mientras que cuando ejerció la función de Administración (sin petición de no responder en la lista azul), 
Rangel-Bernal, Ribes, Valdéz-González \& Pulido-Ávalos

los participantes mostraron una mayor cantidad de este tipo de conductas. Esto también sucedió en el Grupo 8 (de Autoridad por fuerza). En el resto de los grupos que se expusieron a la autoridad por fuerza, los participantes no mostraron conductas desobedientes cuando el experimentador prescribió contingencias, y realizaron un número reducido de respuestas prohibidas cuando el experimentador reguló o supervisó en la situación. Este resultado parece apoyar el efecto reportado por Milgram (1974/2004), quien observó que la sola presencia de una figura de autoridad en la situación experimental evitaba el comportamiento desobediente de los participantes.

Un aspecto interesante, fue que los participantes respondieron más en la lista roja, es decir, realizaron en mayor proporción la conducta prohibida, cuando resolvieron la tarea colectivamente. Este resultado ya había sido reportado por Milgram (1974/2004), quien sugirió que la influencia de un grupo podía liberar del control autoritario a un individuo. En el presente experimento se observó que el grupo facilitó el desafío a la figura de autoridad.

\section{Experimento 2}

En este experimento, a diferencia del Experimento 1, el poder de la autoridad se basó en la riqueza, manipulada explícitamente a través de la posesión y entrega de dulces y golosinas. Las demás características del estudio fueron iguales a las del experimento anterior.

Método

\section{Participantes}

Veinte niños de sexto grado de primaria (10 mujeres y 10 hombres) entre los 11 y los 12 años de edad, que participaron a cambio de dulces y golosinas. Los premios, con su respectivo valor en puntos, se mostraron a los participantes antes de iniciar la sesión experimental.

Materiales y situación experimental

La situación experimental, las tareas y los materiales que se utilizaron fueron similares a los del Experimento 1.

\section{Diseño}

En este experimento, los participantes se distribuyeron al azar en cinco grupos experimentales. Después de la fase de Entrenamiento en Autoridad, los participantes de los primeros tres grupos se expusieron a las condiciones de Prescripción, Regulación y Supervisión respectivamente. Los grupos 4 y 4B se expusieron a la condición de administración de consecuencias. Durante la Fase 3 los participantes trabajaron separados (Individual), mientras que durante la Fase 4, trabajaron simultáneamente en el mismo salón (Colectivo). 
Procedimiento

Fase 1 - Entrenamiento en Autoridad

Fue similar al realizado en el Experimento 1, sólo se modificó la parte del procedimiento referente a la función de administración: en lugar de retirar a los participantes del salón experimental si se comportaban de manera no permitida, en este experimento la figura de autoridad otorgó puntos a los participantes por no presentar las conductas prohibidas y les quitó los puntos ganados cuando lo hicieron, afectando el intercambio de los puntos por dulces y golosinas. Las instrucciones fueron similares a las de esta condición en el Experimento 1, y sólo se cambió lo referente a los puntos:

Al primer equipo que finalice su rompecabezas, o que al acabarse el tiempo haya ensamblado más piezas le voy a dar 500 puntos para cada integrante. Al equipo que quede en segundo lugar le voy a dar 300 puntos para cada integrante. Ustedes podrán intercambiar sus puntos por los premios que quieran. Mientras estén resolviendo los rompecabezas les prohíbo que digan malas palabras, se golpeen, se lastimen, se insulten, griten o levanten la voz a un compañero. Si alguno de ustedes hace alguna de estas conductas le voy a quitar los puntos que gane durante este juego.

Si alguno de los participantes perdía sus puntos por comportarse de la manera no permitida podía seguir armando el rompecabezas de la sesión.

Fase 2- Línea Base y Fases 3 y 4

Las sesiones de Línea Base y las de ejercicio de las funciones del poder en cada grupo se realizaron de la misma forma que en el Experimento 1. En el Grupo 4, la función de Administración se aplicó de manera similar al Grupo 4B del Experimento 1. Se agregó, como control, un grupo en el que se ejerció la función de administración (4B) modificando el componente instrumental de dicha función. Éste consistió en quitar los puntos que hubieran ganado los participantes hasta el momento de encerrar una palabra de la lista roja; después de la administración de esta consecuencia los participantes podían continuar resolviendo la sopa de letras. Si volvían a encerrar una palabra de la lista roja, el experimentador administraba nuevamente la consecuencia quitando los puntos ganados hasta ese momento de la sesión.

\section{Resultados y discusión}

La Figura 5 muestra el número de palabras encontradas en cada lista por los participantes de los grupos 1, 2 y 3 de este experimento. Todos los participantes respondieron en las dos listas durante las tres sesiones de Línea Base. Los participantes 
Rangel-Bernal, Ribes, Valdéz-González \& Pulido-Ávalos

del Grupo 1, expuestos a la condición de prescripción no mostraron respuestas prohibidas después de la línea base, al menos en las sesiones individuales. En las sesiones colectivas los participantes que mostraron el menor número de respuestas en la lista roja fueron los del Grupo 3 (Supervisión). Tres de los participantes del Grupo 1 (1, 2 y 3), y uno del Grupo 2 (Participante 8) perdieron sus puntos en alguna de las sesiones de Entrenamiento en Autoridad, por haberse comportado de manera no permitida. Por último, en el Grupo 3, ninguno de los participantes perdió sus puntos en esta condición.

La Figura 6 muestra el número de palabras encontradas por los participantes de los grupos 4 y 4B. Todos los participantes se mantuvieron respondiendo en ambas listas durante las sesiones de Línea Base. En el Grupo 4, a partir de la sesión en la que el experimentador ejerció la función de Administración (retirar la hoja de la sopa de letras), todos los participantes respondieron por lo menos una vez en la lista roja durante todas las sesiones experimentales. En el Grupo 4B, en el que la función de Administración consistió en quitar los puntos que llevaban ganados hasta antes de responder en la lista roja, el número de respuestas prohibidas desapareció en dos de los participantes (13B y 14B). Tres de los participantes del Grupo 4 (13, 14 y 15) y dos del Grupo 4B (15B y 16B) perdieron sus puntos por realizar conductas prohibidas en el Entrenamiento en Autoridad.

Al parecer, ante una figura de autoridad que basó su poder en la riqueza, las funciones de Regulación y de Administración fueron las menos efectivas para generar conducta obediente en los niños. En el caso de la Administración, fue poco efectiva cuando se ejerció de manera similar a los experimentos anteriores, es decir, retirando la tarea a los participantes cuando encerraban una palabra en la lista roja. En todos los grupos, excepto en el 4, se pudo observar el efecto desinhibidor del grupo en la conducta obediente (Milgram 1974/2004).

Al parecer es muy difícil identificar situaciones en las que se observe el ejercicio puro de los tipos de poder o de sus bases (Russell, 1949; French y Raven 1959). Por ello, aún cuando la figura de autoridad en este experimento basó su poder en la riqueza, en el caso del Grupo 4, al momento de administrar consecuencias utilizando la fuerza (retirar la tarea), no es extraño que se haya observado un patrón de respuestas similar al que se encontró en el Experimento 2, tanto en el grupo de Entrenamiento en Autoridad (Grupo 8) como en el de Familiarización (Grupo 4). En cambio, cuando los participantes del Grupo 4B del presente experimento se expusieron a una figura de autoridad que ejerció la función de administración con base en la riqueza exclusivamente (quitar puntos), se observó una ejecución distinta por parte de los participantes, respondiendo con menor frecuencia en la lista roja. 
Obediencia y cumplimiento en niños escolares

$\oplus$
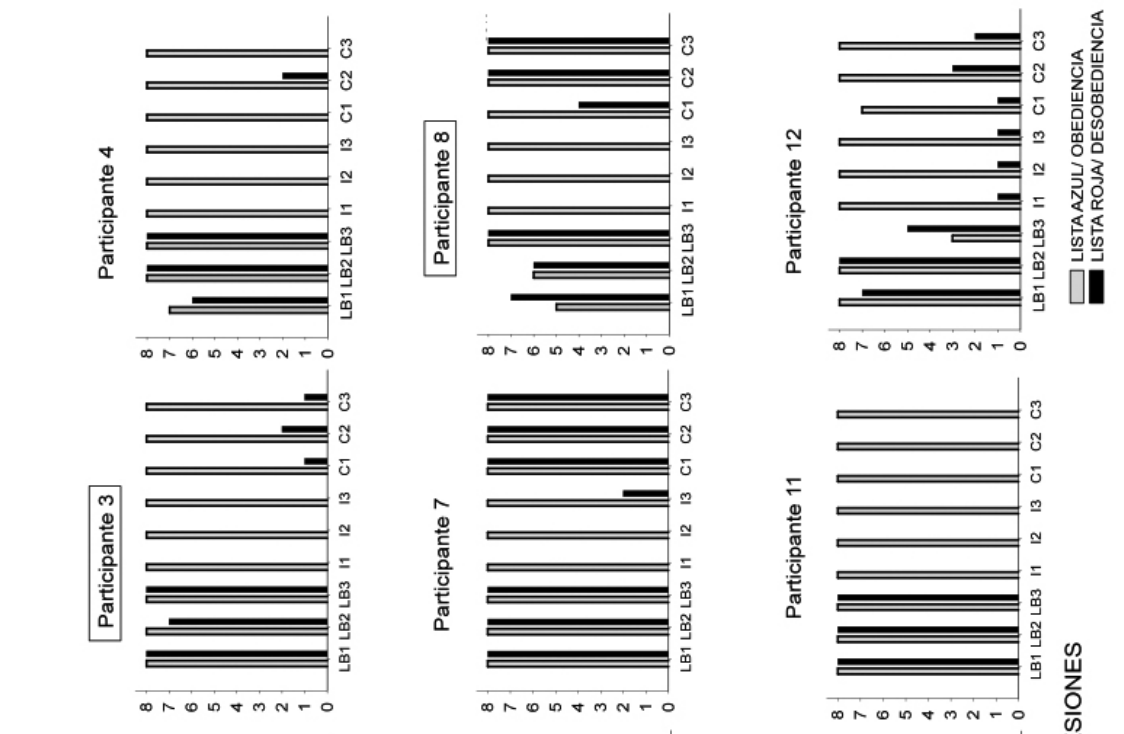

욷흠

ข

.

ํㅣㄹ
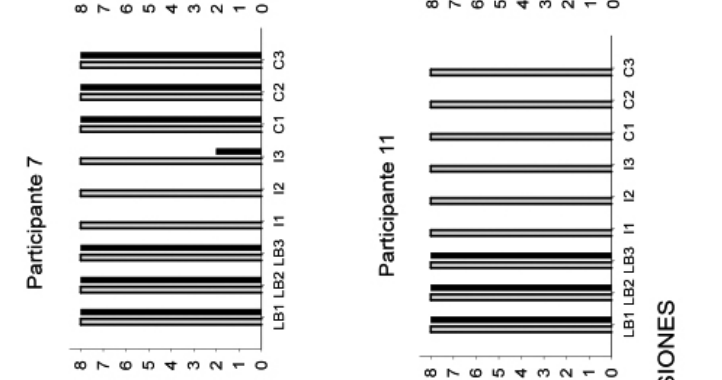

希

ฮ

m $\frac{1}{0}$

$>\cdot \frac{0}{n}$

$\sqrt{2}$

$\bar{x}$

น ำ

ㅎํ음

on

은

U

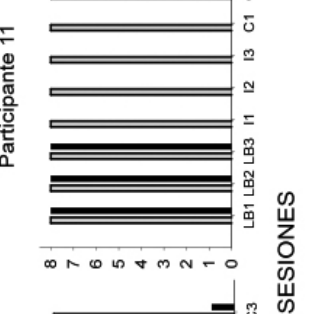

\& $\simeq$ ช

芒

ํㅡ ㄷํㅇ

는은

츤

क ते

으 ह을

¿ $\overline{0}$

$\stackrel{2}{*}$

苞

즌
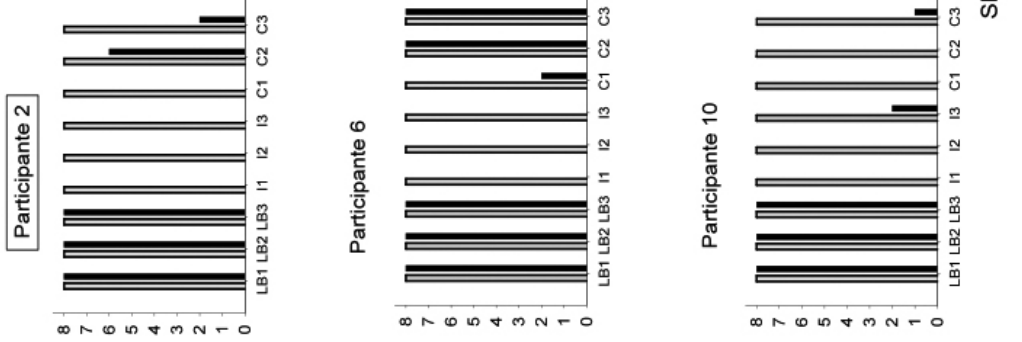

을

ชิ สำ

당 क

誉 $=$

(1) ญ

흥 응

幽

过

() $\frac{0}{0}$

뜬

을 $\dot{2}$

ก กิ

는 는

을

일 을

등 응

乙융

L

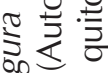

Revista Mexicana de Análisis de la Conducta / Mexican Journal of Behavior Analysis v37 n2 8-2011/11-2011 
Rangel-Bernal, Ribes, Valdéz-González \& Pulido-Ávalos

224
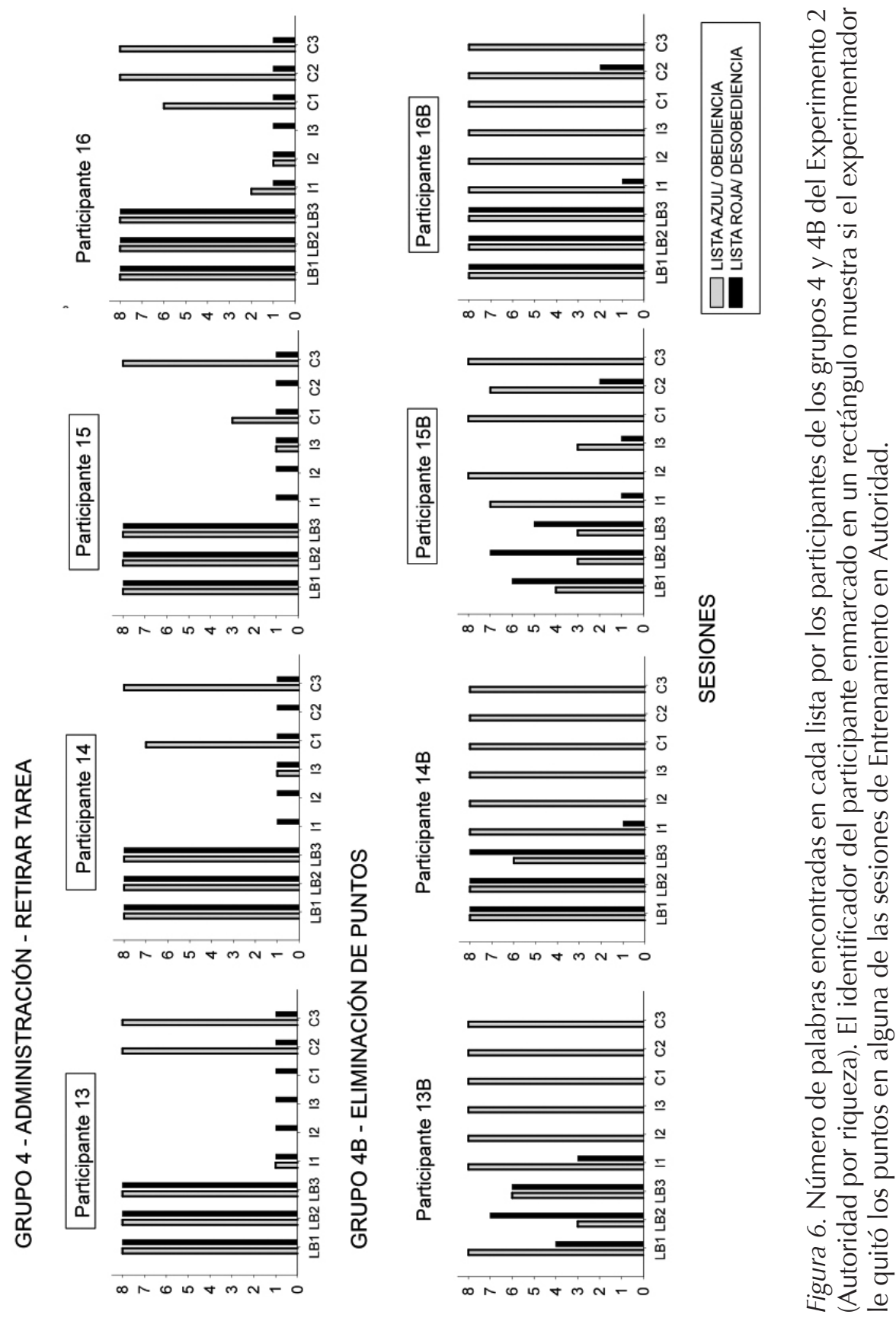

Revista Mexicana de Análisis de la Conducta / Mexican Journal of Behavior Analysis v37 n2 8-2011 /11-2011 


\section{Discusión general}

La realización de estos experimentos permitió la observación de tres efectos principales: 1) un efecto diferencial en la conducta de niños escolares debidos al establecimiento de una figura de autoridad (Entrenamiento en Autoridad) o a la sola presencia del experimentador en la situación (Familiarización); 2) ejecuciones distintas debidas al ejercicio de cada una de las funciones de poder; y 3) diferencias en la conducta de los participantes debidas a la base de poder en la que basó su ejercicio la figura de autoridad (fuerza o riqueza).

En relación con el primer efecto, se observó que los participantes expuestos a condiciones de Familiarización (sin figura de autoridad) mostraron más conductas prohibidas que los expuestos al entrenamiento en autoridad por fuerza. La única excepción fue el Grupo 2 del Experimento 1, en el que el experimentador ejerció la función de Regulación y los participantes mostraron muy pocas respuestas en la lista roja. Este resultado y los de los casos en los que, bajo condiciones de Familiarización, los participantes mostraron cumplimiento ante las peticiones del experimentador, podría deberse a que se asumió, que los participantes no percibirían al experimentador como una figura de autoridad. Sin embargo, el que los participantes hubieran presentado cumplimiento en esta condición, a pesar de perder una gran cantidad de puntos (y de dulces y golosinas), se pudo deber a que el experimentador fuera considerado una autoridad (aún sin el entrenamiento explícito), como lo sugiere el hecho de que por lo menos en las primeras sesiones, los niños se referían a él Ilamándolo 'maestro'. Si éste fuera el caso, en realidad se evaluó el cumplimiento en una situación de poder y no en una de simple influencia como se pensó originalmente (Rangel, 2008; Rangel \& Ribes, 2009a; Ribes et al. 2008). Willer, Lovaglia \& Markowsky (1997) señalaron ya la importancia de distinguir entre las relaciones que se establecen por influencia de las que se establecen por poder. Ante este hecho, es importante explorar el cumplimiento que se presenta entre pares como medida de comparación con los resultados de este experimento.

En cuanto al segundo efecto, en los dos experimentos se pudieron observar ejecuciones diferenciales debidas al establecimiento de las funciones en cada grupo. Al parecer, después de un entrenamiento en autoridad la función de prescripción pareció ser la más efectiva para generar conducta obediente en los niños.

En lo que toca al tipo de poder, los datos obtenidos sugieren que la figura de autoridad por fuerza fue más efectiva que la figura de autoridad por riqueza en la ocurrencia de conducta obediente. Estos resultados apoyan la suposición de Russell (1949) respecto de la desventaja del poder por riqueza ante el poder por fuerza o por conocimiento. Sin embargo, un dato interesante, y que obliga a tomar esta afirmación con precaución, es el que mostraron los participantes del Grupo 4B del Experimento 2. En este caso la eliminación de puntos (riqueza) fue suficiente para disminuir la cantidad de conductas desobedientes en los participantes. 


\section{Referencias}

Ayala, H. E., Téllez, S. G., \& Gutiérrez, M. (1994). Análisis y establecimiento de estilos instruccionales en padres de familia como estrategia de intervención en problemática conductual infantil. Revista Mexicana de Psicología, 11(1), 7-18.

Ayala, H., Chaparro, A., Fulgencio, M., Pedroza, F., Morales, S., Pacheco, A., Mendoza, B., Ortiz, A., Vargas, E., \& Barragán, N. (2001). Tratamiento de agresión infantil: desarrollo y evaluación de programas de intervención conductual multi-agente. Revista Mexicana de Análisis de la Conducta, 27, 1-34.

Ayllon, T., \& Azrin, N. (1968). The Token Economy. A motivational system for therapy and rehabilitation. New York : Appleton Century Crofts.

Azrin, N. H., \& Wexolowski, M. D. (1974). Theft reversal: An overcorrection procedure for eliminating stealing by retarded persons. Journal of Applied Behavior Analysis, 7(4), 577-581. http://dx.doi.org/10.1901\%2Fjaba.1974.7-577

Baron, R.A., \& Byrne, D. (1982). Exploring Social Psychology. (2ª Ed). New York: Allyn and Bacon, Inc.

Blass, T. (1996). Attribution of responsibility and trust in the Milgram obedience experiment. Journal of Applied Social Psychology, 26(17), 1529-1535, available via: http://dx.doi.org/10.1111\%2Fj.1559-1816.1996.tb00084.x

Brant, W. D. (1990). The effects of race and social distance on obedience. Journal of Social Psychology, 112(2), 229-235, available via: http://dx.doi.org/10.1080/ 00224545.1980 .9924324

Burger, J.M. (1986). Increasing compliance by improving the deal: the that's-not-all technique. Journal of Personality and Social Psychology, 51, 177-194, available via: http://dx.doi.org/10.1037//0022-3514.51.2.277

Burger, J.M. (2009). Replicating Milgram: Would people still obey today? American Psychologist, 64(1), 1-11, available via: http://dx.doi.org/10.1037/a0010932

Camacho G., E. (2000). Análisis experimental del intercambio social de díadas de niños en condiciones de cooperación y competencia. Tesis de Maestría no publicada. México: Universidad de Guadalajara.

Carey, R.G., \& Bucher, B. (1981). Identifying the educative and suppressive effects of positive practice and restitutional overcorrection. Journal of Applied Behavior Analysis, 14(1), 71-80. http://dx.doi.org/10.1901\%2Fjaba.1981.14-71

Cialdini, R.B., \& Goldstein, N.J. (2004). Social Influence: Compliance and conformity. Annual Review Psychology, 55, 591-621, available via: http://dx.doi.org/10.1146/ annurev.psych.55.090902.142015

French, J. R. P., Jr., \& Raven, B. (1959). The bases of social power. En D. Cartwright (Ed.) Studies in Social Power, (pp.150-167). Michigan: Ann Arbor.

López, V. F. (1987). Los ámbitos de la normatividad. Conferencia invitada en el 9o. Congreso Mexicano de Análisis de la Conducta, Puebla (México), realizado del 5 al 7 de Octubre. 
Milgram, S. (1974/2004). Obedience to authority. (New Edition). New York: Perennial Classics, available via: http://dx.doi.org/10.1177/001872676501800105

Premack, D. (1962). Reversibility of the reinforcement relation. Science, 136, 255-257, available via: http://dx.doi.org/10.1126/science.136.3512.255

Premack, D. (1963). Rate differential in monkey manipulations. Journal of the Experimental Analysis of Behavior, 6, 81-89. http://dx.doi.org/10.1901/jeab.1963.6-81

Rangel, N. (2008). Un análisis de las relaciones poder-autoridad y sus efectos. Los casos experimentales de la obediencia y el cumplimiento en niños escolares. Tesis doctoral. México: Universidad de Guadalajara.

Rangel, N. (2003). Un estudio experimental de la obediencia en niños. Tesis de maestría. México: Universidad de Guadalajara.

Rangel, N., \& Ribes, E. (2009a). Un análisis experimental del poder y la autoridad. En M. A. Padilla Vargas (Ed.). Avances en la investigación del comportamiento animal y humano, (pp. 141-153). México: Universidad de Guadalajara.

Rangel, N.,\& Ribes, E. (2009b). Level of authority and response cost in the obedience of schoolchildren. Journal of Behavior, Health \& Social Issues, 1(2),51-63.

Ribes Iñesta, E. (2001). Functional dimensions of social behavior: theoretical considerations and some preliminary data. Revista Mexicana de Análisis de la Conducta, 27, 284-305.

Ribes Iñesta, E., Rangel, N., \& López, F. (2008). Análisis teórico de las dimensiones funcionales del comportamiento social. Revista Mexicana de Psicología, 25, 1, 45-57.

Rindt, B. (1997). Effects of interest arousal on compliance with a request for help. Basic and Applied Social Psychology, 19, 49-59, available via: http://dx.doi. org/10.1207/15324839751037138

Rindt, B., \& Strohmetz, D. (2001). Effect of restaurant tipping of presenting customers with an interesting task and of reciprocity. Journal of Applied Social Psichology, 31, 1379-1384, available via: http://dx.doi.org/10.1111/j.1559-1816.2001.tb02678.x

Roberts, M.W., Hatzenbuehler, L.C., \& Bean, A.W. (1981). The effects of differential attention and time out on child non-compliance. Behavior Therapy, 12, 93-99, available via: http://dx.doi.org/10.1016\%2FS0005-7894\%2881\%2980109-8

Robinson, K.E., \& Sheridan, S.M. (2000). Using the mistery motivator to improve child bedtime compliance. Child \& Family Behavior Therapy, 22(1), 29-49, available via: http://dx.doi.org/10.1300/J019v22n01_03

Russell, B. (1949). Autoridad e Individuo. México: FCE.

Wilder, D.A., Harris, C., Reagan, R., \& Rasey, A. (2007). Functional analysis and treatment of noncompliance by preschool children. Journal of Applied Behavior Analysis, 40, 173-177, available via: http://dx.doi.org/10.1901/jaba.2007.44-06

Willer, D., Lovaglia, M.J., \& Markovsky, B. (1997). Power and influence: A theoretical bridge. Social Forces, 76(2), 571-603, available via: http://dx.doi.org/10.2307/2580725 